\title{
Communication and termination: whose choice?
}

\author{
Laura Patterson
}

\section{Introduction}

Communication at the time a woman finds herself pregnant is extremely important. When choosing termination she must have all the facts and information to make an informed choice for herself. This can be extremely difficult if she relies on family and friends for assistance.

\section{Clinical scenario}

A 33-year-old woman attends clinic with her husband and three young children. The husband informs you that his wife does not speak English. He tells you she is pregnant and that she must have a termination, as she could not look after any more children. You notice that her body language suggests she is uneasy. She is fidgeting, looking distressed and avoiding eye contact with you or her husband. The children are quiet and still. You ask the husband to explain that she needs to be examined in a separate room and he is insistent he must be present. You were hoping that he would remain with the children. You then suggest that you can arrange for an interpreter to attend with them so that she can have the choices and procedure fully explained and be examined while he cares for the children. Her husband insists that this is not necessary, as he will translate and the children can stay in the room with a nurse. How will you proceed?

\section{The panel}

Five health professionals (detailed in Box 1) were invited to discuss how they would manage this clinical scenario.

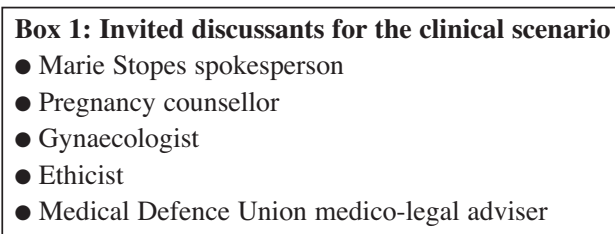

\section{Marie Stopes spokesperson}

This is an opportunity for you to establish a doctor-patient relationship with your patient. It is important to remember that the patient in this context is the woman requiring the termination of pregnancy. Her uneasiness, fidgeting and apparent distress may be for a variety of reasons, including: 1. She may not want a termination.

2. She may be sure about having a termination but have concerns about it; she may have misconceptions, or may have experienced unsafe and/or illegal abortion in her country of origin.

3. She may have come from a culture where her body language gives you the impression that she is distressed; however, you may be misinterpreting her body language.

The only way that you can find out the reasons for her apparent distress is to communicate with her. If this is not

J Fam Plann Reprod Health Care 2005; 31(1): 75-76

Swindon Health Centre, Swindon, UK

Laura Patterson, MRCGP, DFFP, General Practitioner and Associate Specialist in Family Planning

Correspondence to: Dr Laura Patterson, Swindon Health Centre, Carfax Street, Swindon SN1 1ED, UK. E-mail: laurapatson@yahoo.co.uk possible with the husband present, then you must insist on speaking with her privately. If her English is not adequate, then you must also insist on arranging a further appointment with an interpreter.

By demonstrating to her that you regard her feelings as important you will increase the level of trust that she has for you as her doctor, and empower her to discuss any concerns she may have about having a termination.

It is important, however, not to delay her access to termination services. If an interpreter is needed, make an appointment as soon as possible.

\section{Pregnancy counsellor}

The woman has attended as a client of the service. This situation is a delicate one in that it appears that the woman is deferring to her husband. Not only does the woman appear deferential but also her children appear very quiet and subdued. The picture is one of control by the husband who is requesting a termination of pregnancy. It is difficult to ascertain whether this is the wish of the woman. Therefore, it is important to find out what she is thinking. In order to avoid alienating the husband, I would ask him what his response to the pregnancy is and, after listening, ask if it is possible for him to include his wife in the conversation. However, without an interpreter it is difficult to establish whether he is reporting back what she is saying. Although he has refused an interpreter I would suggest to him that there is a standard within the service where a woman is always offered an interpreter so that she can voice her views. I would also discuss that it would be impossible to proceed with referral for termination without this supportive service. It would be important to reflect back to the husband that his wife appears distressed and that if she is not able to express her views then there is an increased chance of her having regrets and emotional problems following a termination. I would offer again to phone the interpreting translation service. One caveat to the above that is worth pondering: is the woman in an abusive or violent relationship? She may be happy or unhappy in accessing a termination but just be terrified of her husband. There is a need, therefore, to be aware of other referral agencies such as women's aid, etc. It may be that the family needs counselling or possibly some social work support depending on what the home situation is.

\section{Gynaecologist}

This is a difficult problem, but my overriding responsibility is to establish the reasons the woman has consulted me. Her wishes are paramount. The picture as described would suggest a conflict of views; the woman is clearly distressed and the children are quiet - perhaps there have been angry scenes at home. I would need to establish that she is indeed pregnant and whether her husband is the father; perhaps she has had an affair or has been the victim of a sexual assault. This information would need to be gathered from the woman herself without her husband being present. However, I would be mindful that speaking with her on her own may well antagonise the situation at home causing further distress and perhaps abuse.

I would, therefore, very carefully explain my responsibilities and duty of care to his wife. I would point out that the only way I can do this is to speak with her myself without her husband being present. I would not 
agree to a request for termination of pregnancy without her consent; there must be no coercion from a third party. I would, therefore, insist on obtaining a hospital interpreter.

If he agrees to this, I would then fully explore the situation the woman finds herself in. Does she want to continue the pregnancy and what help can I offer to support her in this decision? Why does he want her to have a termination? Are there relationship difficulties and has she been subjected to domestic violence? Does she need help? Is she depressed? Are there supportive family or friends? Should social services be involved or does she need details of a local refuge?

If he does not agree to me seeing his wife with an interpreter, I would have to curtail the appointment and decline his request. My further actions would depend on his response. If he were to become violent I would contact the police. If he accepts my view I would contact the woman's general practitioner (GP) and express my concerns about the family. The GP may already be aware of the family. I would voice my concerns about the safety of the woman and her children. I would see if social services have a record of the family on file.

Whatever the outcome of the appointment, I would offer them both the opportunity of seeing me again to further discuss the situation and offer my continuing support. If appropriate, I would give her/them details of outside agencies that might help, for instance Relate or Victim Support.

\section{Ethicist}

The scenario seems to imply that the woman may not be in agreement with her husband's request for a termination. However, this may not be the case at all; the woman may simply feel embarrassed because her husband is discussing the intimate details of their life together. Alternatively, she might want the termination but is distressed for other (for example, religious) reasons. It is important to bear in mind that your own cultural context influences the way you interpret body language.

However, in order to make the best possible assessment it would be preferable to speak to the woman without her husband present. It is, of course, good policy to offer an independent interpreter, especially in potentially sensitive situations where there may be conflict of interests, but can you insist on it?

It strikes me that in this case you could justifiably insist that the woman is seen without her husband present, as you would thereby stand a better chance of assessing whether or not she is being coerced, in any way.

Even if this is the case, however, and you ascertain that the woman would rather have the baby but that her husband is putting pressure on her to have a termination, it is not immediately obvious how to proceed.

For consent for the termination to be valid, the patient should be competent, fully informed and free from coercion; but what if the woman says that her life would not be worth living if she went against her husband's wishes, and that is why she feels she has no choice but to terminate the pregnancy?

Would it then be in her best interests to perform the termination even though you knew it wasn't what she really wanted? Or conversely, would her best interests be served by refusing her the termination on the grounds that she was being coerced?

While a doctor's legal duty is to treat patients in their best interests, there is no legal or professional guidance on how to interpret what exactly a patient's best interests might be. Cases such as this one highlight the difficulty of how best interests can be determined and pursued.

\section{Medical Defence Union medico-legal adviser}

The General Medical Council (GMC) advises, in their publication Good Medical Practice, that: “... as a doctor you must make the care of your patient your first concern". In their guidance on consent, the GMC advises doctors that: "You should do your best to ensure that patients have considered the options and reached their own decision" and "Patients must be given sufficient information, in a way that they can understand, to enable them to exercise their right to make informed decisions about their care".

If you feel that it is in the patient's best interests to have a discussion without her husband being present, or with a professional interpreter, then you should arrange for that. The husband could be reassured that he will be included in any discussions thereafter, with his wife's consent. Good communication with the husband, making clear that his wife's best interests are the primary concern of the medical team and that he will be given every opportunity to support his wife, may reassure him and may also help to avoid a complaint. You should keep careful notes of your discussions.

If the husband were unhappy with your proposed plan of management and wished to complain then he should be advised of how he can raise any concerns through the Trust's complaints procedure.

CC Copyright Medical Defence Union 2004

\section{Discussion}

The overriding theme of the panellists' discussion seems to be that of good communication with the woman and her husband. It is important to give them both an opportunity to discuss and consider their concerns and feelings. Health professionals should avoid making assumptions and they must assimilate all the cues. Both the woman and her husband need to be put at their ease in this most difficult of situations.

What would you have done faced with this situation? We welcome your comments.

\section{Acknowledgements}

The author would like to thank the panel members for their input. A listing of the individual panel members who have contributed to the Clinical Conundrum section of the Journal is published annually. (NB. The medico-legal advisor who responded on behalf of the Medical Defence Union was Hugh Stewart.)

\section{LETTERS TO THE EDITOR}

Letters to the Editor are welcome and generally should not exceed 600 words or cite more than five references. For comments on material published in the most recent issue of the Journal, correspondence should be received within 4 weeks of dispatch of that Journal to be in time for inclusion in the next issue. When submitting letters correspondents should include their job title, a maximum of two qualifications and their address(es). A statement on competing interests should also be submitted for all letters. Letters may be submitted to the Editor or the Journal Editorial Office (details on page 1). 